\title{
On The Dynamic Dependence Between Oil Prices and Stock Market Returns: A Copula-GARCH Approach
}

\author{
Mondher Kouki (Corresponding author) \\ Faculty of Economic sciences and Management of Tunis \\ University of Tunis El Manar, Tunisia \\ E-mail: mondher.kouki@fsegt.utm.tn \\ Samia Ben Massoud \\ Faculty of Economic sciences and Management of Tunis \\ University of Tunis El Manar, Tunisia \\ Achouak Barguellil \\ Faculty of Economic sciences and Management of Tunis \\ University of Tunis El Manar, Tunisia
}

Received: January 20, 2019

Accepted: February 23, 2019 Published: March 25, 2019

doi:10.5296/ijafr.v9i1.14243

URL: https://doi.org/10.5296/ijafr.v9i1.14243

\begin{abstract}
This study investigates the conditional dependence structure between crude oil price and stock returns markets in twelve oil importing and exporting countries from 1999 to 2016 by using the conditional copula-GARCH model. Our empirical results indicate the superiority of our approach and show evidence of significant tail dependence of the returns in unstable financial environment.
\end{abstract}

Keywords: Crude oil, Stock markets, Contagion, Copulas

\section{Introduction}

The Oil market, considered to be the largest international raw material market, has witnessed major disruptions since the 1970s. These disruptions ultimately generated uncertainty risks 
about the world's economic stability. Then, it is useful to determine how the oil market functions and particularly how prices are determined. Bearing this in mind, we set ourselves to determine the factors behind the fluctuations of oil prices. Studying the effects of oil prices on the Gulf Cooperation Council (GCC) stock markets is interesting for many reasons. First, the GCC countries are the main players in the international oil market. In fact, stock markets are likely to be sensitive to oil prices fluctuation. Second, the GCC markets are different to the markets that are often examined by previous studies, as these markets are relatively poorly integrated in the global financial market. Moreover, they are extremely sensitive to regional political events.

The Gulf countries hold $64 \%$ of the share of activities related to Islamic finance. This is explained by liquidity excess and abundance of oil resources. Next to them, we find Malaysia (28\%), the United States and Europe (1\%), while the rest of the world holds (7\%) (HSBC Amanah, 2012). A review of the literature shows that research on the relationship between oil prices and stock markets is very scanty. Particularly, few studies have focused on stock markets in Gulf countries. These studies have essentially examined the short-term interaction between oil prices shocks and stock market returns.

Accordingly, our study examines the interdependencies between oil prices and stock market indices. Literature-wise, we contribute to the study of extreme co-movements between these variables using the Copula-Garch approach and oil prices and stock market returns distributions. Our methodology greatly differs from those used in the literature to examine dependency between financial markets. As a matter of fact, oil prices markets may incur changes generated in stock markets. Consequently, important investment decisions may be taken in response to such dynamics.

The remainder of this article is organized as follows. Section 2 presents a rapid literature review about the dynamic dependence between oil prices and stock market returns. The Section 3 will refer to the copula's approach. We will explain our data and methodology in section4. Our empirical results are provided in section 5.

\section{Literature Review}

During the last decades, numerous studies have focused on determining the relationship between oil prices and economic activity. Importantly, these studies found that oil price shocks have significant effects on the macroeconomic variables of most developed and emerging countries (Gronwald (2008) and Lardic and Mignon (2008)). Whether contagion effects exist is an important economic issue for many economic agents including policymakers and investors. If severe financial shocks and financial crises are contagious and quickly transmitted from one market to another, a rigorous plan for risk management is strongly recommended as the financial performance of most economic sectors may be seriously impacted. Moreover, the contagion effects often lead to significant changes in the economic fundamentals that govern the dynamics of the markets in question. In general, the contagion term is used by media qualify the situation in which there is a considerable increase in cross-market links after a shock and the earlier studies of the related literature 
mainly rely on the concept of correlation breakdown to detect contagion effects (i.e., a significant increase in the cross-market correlation during periods of crisis).

For example, Bertero and Mayer (1989) and King and Wadhwani (1990) find an increase in correlation of stock returns during the 1987 depression. However, as noted by Boyer and al. (1999), the examination of contagion by changes in correlation structures may be biased because computing correlation between two extreme outputs-conditioned random variables would probably lead to strong correlation during a downside market period, even though observable data retain a constant correlation. Forbes and Rigobon (2002) generalize the conditional heteroscedasticity sensitive tests of Boyer and al. (1999) to study the contagion around the three important crises (the 1987 depression, the 1994-1995 Tequila crises in Mexico and the 1997-1998 Asian financial crises). After adjusting for heteroscedasticity, Forbes and Rigobon (2002) fail to detect a correlation breakdown during any of the three crises, and they conclude on the absence of contagion, but on the presence of a simple temporal continuation of excessive dependence-driven volatility among international markets, which already occurs in stable periods.

Examining asymmetry of shock signs goes back to the studies of Mork (1989) who showed that "it is increases in oil prices, rather than decreases that play a major role". Mork's finding shows that multi-sign oil shocks may have an impact on economic variables in an asymmetrical way. In fact, we anticipate that markets react differently in response to whether a shock is positive or negative. Along the same line of reasoning, Jones and Kaul (1996) use quarterly data to check whether reaction of global stock markets towards oil prices fluctuation may be explained by a change in expected returns in countries like USA, Japan and Canada. The authors found a stable and a negative relationship between oil prices evolution and stock indices returns. This relationship is more significant for Japan than for Canada. Additionally, the authors show that current prices and lagged oil prices negatively affect stock returns.

Sadorsky (1999) is the first scholar who has worked on the issue of asymmetry in the relationship between oil price and sock returns. The author found evidence indicating that it is oil prices volatility, rather than interest rate, which plays a greater role in explaining behavior patterns of stock indices in the United-States. As a matter of fact, impulse response functions for the estimated VAR shock show that positive shocks in the form of an increase in oil prices greatly affect the stock market index. Moreover, a negative shock in the form of a decrease in oil prices does not have the same effect on the index's variation. Regnier (2007), comparing volatility of commodity prices in the United-States, found that oil prices are more volatile than $95 \%$ of the other commodities. Similarly, Park and Ratti (2008) examined the respective individual effects of oil prices and their volatility on stock market returns in the United-States and 13 industrial European countries. Using the same methodology of Sadorsky, the authors show that oil price shocks have a statistically significant effect on stock market returns in a contemporaneous fashion in the same month or with a one-month lag.

Moreover, several studies examined the relationship between oil prices and some macroeconomic variables in Nigeria (Olomola and Adejumo, 2006, Akpan, 2009, Aliyu, 2009, 
Aliyu, 2011, Mahmoud (2009), Chukwu, 2011). However, few studies have examined the relationship between exchange rate and oil prices. Indeed, Olomola and Adejumo (2006) found that oil shocks led to exchange rate valuation in Nigeria. Recently, Iwayemi and Fawowe (2011) found that if oil shocks have no significant effect on the real exchange rate, negative oil shocks do affect the real exchange rate. Autoregressive vector models, co-integration, causality, GARCH and exponential GARCH models have been used to examine the dynamics of oil prices (Narayan et al, 2008; Ghosh, 2011).

Recent studies agree that there is need to go beyond the linear modeling approach to examine the contagion effects. For example, while Longin and Solnik (2001), Hartman et al. (2000) and Bae et al. (2003) make use of the extreme value theory models, other studies such as Ramchand and Susmel (1999), Ang and Bekaert (2002), and Chesney and Jondeau (2000) employ the regime-switching models. Notice that the first approach deals with the dependence structure of extremely large (positive and negative) returns, and the second focuses more on the regime-shift behavior through the detection of structural breaks in variance.

Alternatively, copulas, which are functions that link multivariate distribution functions to their one-dimensional marginal distributions (Nelsen, 1999), have also been recently used by several studies to detect the joint tail behavior of asset returns across national markets and the possibly resulting contagious effects. These studies assess that copulas provide a flexible and efficient tool for describing the nonlinearity, the tail behavior and asymmetric dependence of asset returns. For instance, De Melo Mendes (2005) uses extreme value copulas to study the extreme dependence among seven most important emerging markets and shows some evidence of asymmetry in the joint co-exceedances for the majority of 21 pairs of markets considered. Caillault and Guegan (2005) use the Student and Archimedean copulas to analyze the dependence structure of the three Asian emerging markets and find evidence of symmetric dependence for Thailand-Malaysia pair and asymmetric dependence for Thailand-Indonesia and Malaysia-Indonesia pairs over the period from 1987-2002. Rodriguez (2007) measures the contagion from a mixture of copulas with time-varying parameters in a regime-switching environment, and finds evidence of changing dependence during periods of turmoil. There is also evidence of increased tail dependence and asymmetric dependence for the Asian markets, but symmetric and tail independence for the Latin American markets. However, the presence of structural breaks in the tail dependence as a dimension of the contagion phenomenon leads to suggest that the rejection of the correlation breakdown hypothesis does not imply a stable dependence structure. Aloui et al. (2011) investigate the potential of contagion during the recent global crisis for the BRIC and the US markets. They employ several copula functions that capture not only the fatted tail behavior but also the linear and nonlinear interdependences between market returns. Their main results reveal that the time-varying tail dependence is stronger for commodity-price dependent markets than for finished-product export-oriented markets. This dependence is also highly persistent for all market pairs during both bullish and bearish markets. Some other studies also apply copulas to the investigation of dependence structure in other assets markets. See, for example, Patton (2001) for foreign exchange markets, Grégoire et al. (2008) for energy markets, Reboredo 


\section{Macrothink}

International Journal of Accounting and Financial Reporting

ISSN 2162-3082

2019, Vol. 9, No. 1

(2011) for crude oil markets, Ning (2010) for stock and foreign exchange markets, and Aloui et al. (2013) for crude oil and foreign exchange markets.

Overall, classical statistical measures of dependence like the linear correlation coefficient is not a good indicator of market interdependence over time, especially in cases where the markets under consideration exhibit nonlinear and asymmetric dependence in the tails of the return distributions. That is to say, the linear correlation is unable to predict the probability of joint booms and/or joint crashes of studied markets under the effects of extreme conditions such as financial turbulences or crises. In this article, we also use copulas to address the issue of conditional dependence between Oil markets. As stated earlier, copulas are flexible enough to detect nonlinear patterns in the conditional dependence structure of random variables whose dynamics can be governed by different marginal distributions.

\section{Theoretical Background of the Copula Approach}

This section presents the copula approach, marginal models, and estimation issues. The initial objective is to test the volatility between the stock markets and Oil prices, using the VAR (1)-GARCH $(1,1)$ model which allows for transmission in volatility, and to test the dependence between financial returns using copula functions. The next, we use a GJR version of GARCH based on a combination of two Student and Clayton copulas to estimate Value-at-Risk.

\subsection{ARMA-GARCH Model}

The mixture of ARMA-GARCH model is similar to the mixture of AR-GARCH model proposed in (Wong et al., 1998). Specifically, each component of the mixture model can be denoted as a normal ARMA series.

$$
\begin{gathered}
X_{t}-c_{0}=\sum_{i=1}^{P} \alpha_{0 i}\left(X_{t-i}-c_{0}\right)+e_{t}-\sum_{j=1}^{Q} b_{0 j} e_{t-j} \\
e_{t}=\sqrt{h_{t}} \eta_{t} \\
h_{t}=\omega_{0}+\sum_{i=1}^{q} \alpha_{0} e_{t-i}^{2}+\sum_{j=1}^{p} \beta_{0 j} h_{t-j}
\end{gathered}
$$

The process $\left\{X_{t}\right\}$ is said to be an ARMA (p, q) process with mean $\mu$ if $\left\{X_{t}-\mu\right\}$ is an ARMA $(\mathrm{p}, \mathrm{q})$ process. The time series $\left\{\mathrm{X}_{\mathrm{t}}\right\}$ is said to be an autoregressive process of order $\mathrm{p}$, and a moving-average process of order $q$. The $\operatorname{GARCH}(\mathrm{p}, \mathrm{q})$ model is strictly stationary with finite variance when the conditions $\omega>0$, and $\beta \mathrm{j}<1$ are required. We can see the GARCH model has similar pattern with ARMA model, which shows we can derive GARCH process using similar theory and method with ARMA.

Where $\mathrm{h}=0$ indicates that we cannot reject the null hypothesis at the $5 \%$ significance level. 


\section{Al Macrothink}

\subsection{Copula Functions}

The Conditional copula was based on the Sklar's (1959) dependency theory. We employ the Sklar's Theorem.

The theorem of Sklar is described as follow: let $\mathrm{F}$ denote an $\mathrm{n}$-dimensional distribution function with margins $F_{1}, \ldots, F_{d}$. The copula $C$ related to $F$ is written:

$$
\begin{gathered}
C\left(x_{1}, x_{2}, \ldots \ldots, x_{d}\right)=C\left(F_{1}\left(x_{1}\right), F_{2}\left(x_{2}\right), \ldots \ldots \ldots \ldots, F_{d}\left(x_{d}\right)\right) \\
=F\left(F_{1}^{-1}\left(x_{1}\right), F_{2}^{-1}\left(x_{2}\right), \ldots \ldots \ldots, F_{d}^{-1}\left(x_{d}\right)\right) \\
=F\left(x_{1}, x_{2}, \ldots, x_{d}\right) \\
\lambda_{u}=\lim _{u \rightarrow 1} \operatorname{Pr}\left[X \geq F_{X}^{-1}(u) / Y \geq F_{Y}^{-1}(u)\right]=\lim _{u \rightarrow 1} \frac{1-2 u+C(u, u)}{1-u} \\
\lambda_{L}=\lim _{u \rightarrow 0} \operatorname{Pr}\left[X \geq F_{X}^{-1}(u) / Y \geq F_{Y}^{-1}(u)\right]=\lim _{u \rightarrow 0} \frac{C(u, u)}{1-u}
\end{gathered}
$$

Where $F_{X}^{-1}$ and $F_{Y}^{-1}$ are the marginal quantile functions and where $\lambda_{u}, \lambda_{L} \in[0,1] \lambda_{L}=0$ then, there is no lower tail dependence. If $\lambda_{u}=0$ then, there is no lower tail dependence.

\subsection{Copula Parameter Estimates}

We present five types of dependence structures, namely Gaussian Copula, student Copula, Clayton Copula, Frank copula and Gumbell copula to estimate the joint distribution.

The Gaussian copula is the copula of the multivariate normal distribution which is defined by the following equation:

Gaussian copula is defined as follows:

$$
C_{\rho}\left(u_{1 t}, u_{2 t}, \ldots ; u_{n t}\right)=\Phi_{p}\left(\phi^{-1}\left(u_{1 t}\right), \phi^{-1}\left(u_{2 t}\right), \ldots, \phi^{-1}\left(u_{n t}\right)\right)
$$

$\phi$ : Function of the normal distribution $N(0,1)$; and $\phi^{-1}$ is the inverse's function of the normal cumulative distribution. $\Phi_{p}$ is the distribution the centered gaussian vector $(\mathrm{X} ; \mathrm{Y})$ of the covariance matrix

$$
\left(\begin{array}{ll}
1 & \rho \\
\rho & 1
\end{array}\right) \Phi_{p}=\int_{-\infty}^{x} \int_{-\infty}^{y} \frac{1}{2 \pi \sqrt{\left(1-\rho^{2}\right)}} \exp \left[-\frac{\left(s^{2}+t^{2}-2 \rho s t\right)}{2\left(1-\rho^{2}\right)}\right] d s d t
$$




\section{MIMacrothink}

To capture the fat tail property, we introduce the multivariate student's t Copula which shows more observations in the tails than the Gaussian.

The Student t-copula is defined as follows:

$$
\begin{gathered}
C\left(u_{1 t}, u_{2 t}, \ldots, u_{n t}\right)=T_{\rho, k}\left(T_{\rho}^{-1}\left(u_{1 t}\right), T_{\rho}^{-1}\left(u_{2 t}\right), \ldots . ., T_{\rho}^{-1}\left(u_{n t}\right)\right) \\
t_{\rho, v}(x, y)=\int_{-\infty}^{x} \int_{-\infty}^{y} \frac{1}{2 \pi \sqrt{1-\rho^{2}}}\left(1+\frac{s^{2}+t^{2}-2 \rho s t}{v\left(1-\rho^{2}\right)}\right)^{-\frac{v+2}{2}} d s d t
\end{gathered}
$$

$t_{\rho, v}$ is a standard multivariate $\mathrm{t}$ distribution, the correlation $\rho, v$ is the degrees of freedom.

It is very close to a Gaussian with strong correlations for movements with similar signs.

The relationship that applies for Kendall's tau for a Gaussian copula applies as well for Student copula.

The $t$ copula is a student copula which joins the marginal $t$ distributions with same degrees of freedom to the bivariate $\mathrm{t}$ distribution. The $\mathrm{t}$ Student copula generalizes the bivariate $\mathrm{t}$ distribution because we can adopt any marginal distribution.

The Joe-Clayton copula function is given by the following cumulative distribution function $(\mathrm{CDF})$ :

$$
C_{\theta}\left(u_{1}, u_{2}, \ldots . ., u_{n}\right)=\left(u_{1}^{-\theta}+u_{2}^{-\theta}+\ldots+u_{n}^{-\theta}-n+1\right)^{-1 / \theta}
$$

Its generator is:

$$
\phi(x)=\frac{u^{-\theta}-1}{\theta}
$$

At this level, copulas have been proved to be a good technique to represent dependence between variables contribution to the two models of the system: the simple and the complex. In reliability system models, they alternate between whether common reasons are unknown or destined to be modelled. The relevant literature is abundant.

The frank copula is described by the following equation:

$$
C_{\text {Frank }}\left(u_{1}, u_{2} ; \lambda\right)=\frac{-1}{\lambda} \log \left(\frac{\lambda\left(1-e^{-\lambda}\right)-\left(1-e^{-\lambda u_{1}}\right)\left(1-e^{-\lambda u_{1}}\right)}{1-e^{-\lambda}}\right)
$$

Where $\lambda \in(-\infty, 0) \cup(0,+\infty)$

The Gumbel copula was introduced in Hougaard (1986), it is also known as the Gumbel_Hougaard family. The CDFs are defined by the following: 


$$
\begin{gathered}
C_{\text {Gumbel }}\left(u_{1}, u_{2} ; \delta\right)=\exp \left(-\left(\left(-\log u_{1}\right)^{\delta}+\left(-\log u_{2}\right)^{\delta}\right)^{\frac{1}{\delta}}\right) \\
C_{\text {Rotated-Gumbel }}\left(u_{1}, u_{2} ; \delta\right)=u_{1}+u_{2}-1+C_{\text {Gumbel }}\left(1-u_{1}, 1-u_{2} ; \delta\right)
\end{gathered}
$$

And $\delta$ is the parameter which determines the correlation of random variables.

\subsection{Extreme Value Theory (EVT)}

Juri and Wuthrichts (2002) determine copula by Extreme value Theory (EVT), Embrechts et al. (2003) used copula to estimate VAR in the worst case scenarios. We used Matlab codes to evaluate our model. The Matlab codes written by Patton (2002, 2006a, 2006b) and Sheppard (2006) for a copula are references that we used to estimate VaR of our model. The multivariate Quantile GARCH copula is computed with a parallel two-step maximum probability compared to the method used by Bauwens et al. (2006).

We standardize the individual residuals of our GJR-GARCH version as varied by the empirical semi-parametric $\mathrm{CDF}$ and then adapt the copula to the transformed data. We calculate the empirical VaR (Value at Risk) and CVaR (Conditional Value at Risk) of an equally weighted portfolio.

Once the marginal distributions of filtered residuals were fitted using a GPD approach for tails distribution and a Gaussian kernel for the interior of distribution, the next stage was to estimate the parameters of dependence structure for the analyzed portfolio. Isolating the effects of marginal distribution, we have estimated dependence existent among the four currencies. In fact this is the copulas' job: to capture the interaction among the portfolio' assets by isolating the individual behavior of each asset.

We focus on distribution of losses beyond a given threshold:

$$
F_{\mu}(y)=P\{X-\mu \leq y / X \succ \mu\}
$$

For distributions checking extreme value theorem and for a threshold $\mathrm{u}$ enough large, there is $\mathrm{x}$, b such that $\mathrm{F}_{\mathrm{u}}$ converges towards a generalized Pareto Distribution.

$$
\begin{gathered}
F_{\mu}(y)=G_{\xi, \beta}(y) \\
G_{\xi, \beta}(x)=\left\{\begin{array}{l}
1-(1+\xi x / \beta)^{-1 / 5} \xi \neq 0 \\
1-\exp (-x / \beta) \xi=0
\end{array}\right.
\end{gathered}
$$

If $\mathrm{n}$ is the total number of the sample and $\mathrm{N}_{\mathrm{u}}$ the number of values exceeding $\mathrm{u}$, then

$$
\widehat{F}(x)=1-\frac{N_{u}}{N}\left(1+\xi \frac{x-\mu}{\widehat{\beta}}\right)^{-1 / \xi}
$$




$$
\overline{\operatorname{VaR}_{q}}=u+\frac{\widehat{\beta}}{\bar{\xi}}\left(\left(\frac{n}{N_{u}}(1-q)^{-\bar{\xi}}-1\right)\right)
$$

We may also estimate loss forecast in case of exceeding VAR.

$$
\begin{gathered}
E S_{q}=V A R_{q}+E\left[X-\operatorname{VaR}_{q} / X \succ \operatorname{VaR}_{q}\right] \\
\frac{E S_{q}}{V a R_{q}}=\frac{1}{1-\xi}+\frac{\beta-\xi u}{(1-\xi) \operatorname{VaR} R_{q}}
\end{gathered}
$$

\section{Data and Methodology}

We empirically examine the interaction of oil and stock prices. The database consists of increments from 12 countries (USA, Japan, China, Germany, France, Italy, Spain, Kuwait, Qatar, Saudi Arabia, and Russia). We consider the Brent crude oil price rather and the West Texas Intermediate (WTI) crude oil price. The study makes use of daily returns of market indices during the period from January 1, 1999 until January 1, 2016.

These data are calculated on the stock market returns and crude oil price by taking the difference in the logarithm of the two following daily prices. The descriptive statistics verify the series are reported in Table 1.

Table 1a. Summary statistics of market returns for crude oil-importing countries

\begin{tabular}{llllllll}
\hline & US & Japan & China & Germany & France & Italy & Spain \\
\hline Mean & 0.0001 & 0.0003 & 0.0002 & 0.0003 & 0.00001 & -0.0001 & -0.0017 \\
\hline Std.Dev. & 0.0115 & 0.0150 & 0.0160 & 0.0161 & 0.0161 & 0.0168 & 0.0160 \\
\hline Skewness & -0.0662 & -0.2115 & -0.2870 & -0.3196 & 0.0090 & -0.0786 & 0.0770 \\
\hline Kurtosis & 11.025 & 7.2078 & 7.8229 & 69.077 & 8.8085 & 8.2584 & 9.4780 \\
\hline Jarque-Bera & 11938. & 3314.0 & 4371.0 & 809092.4 & 6251.65 & 5128.1 & 7780.20 \\
\hline Probability & $(0.000)$ & $(0.000)$ & $(0.000)$ & $(0.000)$ & $(0.000)$ & $(0.000)$ & $(0.000)$ \\
\hline
\end{tabular}




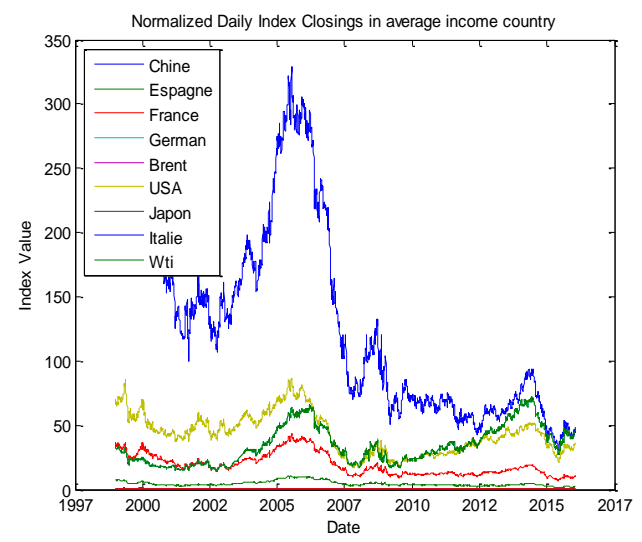

Figure 1a. Prices dynamics for crude oil-importing countries

Table 1b. Summary statistics of market returns and oil price for crude oil exporting countries

\begin{tabular}{lllllll}
\hline & SaudiArabia & Russia & Kuwait & Qatar & Wti & Brent \\
\hline Mean & 0.0003 & 0.0005 & 0.0001 & 0.0004 & 0.0001 & 0.0001 \\
\hline Std.Dev. & 0.0148 & 0.023 & 0.0187 & 0.0250 & 0.024 & 0.022 \\
\hline Skewness & -0.647 & -0.299 & -0.443 & -0.512 & -0.140 & -0.131 \\
\hline Kurtosis & 17.69 & 11.27 & 10.37 & 610.31 & 7.288 & 8.071 \\
\hline Jarque-Bera & 40303.7 & 12766.7 & 10233.5 & 6834.25 & 3422.51 & 4779.2 \\
\hline Probability & $\mathbf{( 0 . 0 0 0 )}$ & $\mathbf{( 0 . 0 0 0 )}$ & $\mathbf{( 0 . 0 0 0 )}$ & $\mathbf{( 0 . 0 0 0 )}$ & $\mathbf{( 0 . 0 0 0 )}$ & $\mathbf{( 0 . 0 0 0 )}$ \\
\hline
\end{tabular}

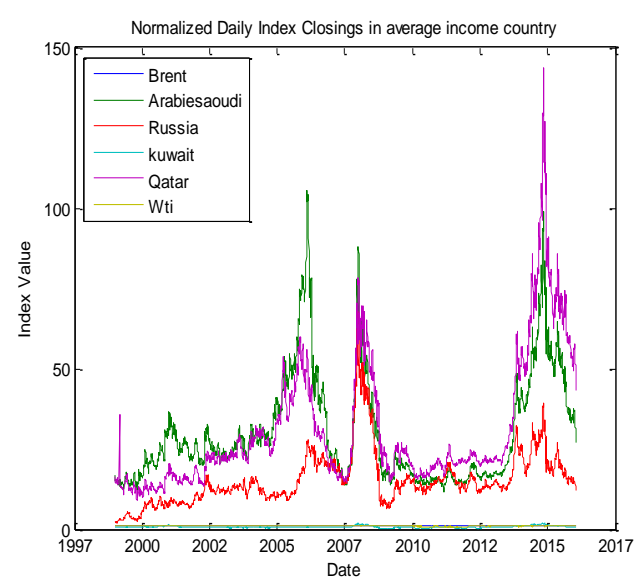

Figure 1b. Prices dynamics for crude oil-exporting countries

The figures $1 \mathrm{a}$ and $1 \mathrm{~b}$ present the countries crude oil price import and crude oil export, reporting the evolution of nominal value invested at the beginning of the period in each country. These curves indicate relative movement of prices for each increment. The initial value of each increment has been standardised into units to ease the comparison of performances with current performances. 


\section{MInstitute $\begin{aligned} & \text { Macrothink } \\ & \text { Instion }\end{aligned}$}

International Journal of Accounting and Financial Reporting

ISSN 2162-3082

2019, Vol. 9, No. 1

To assess distribution and stochastic properties of returns, first we look into some descriptive statistics on the returns of the countries presented in Table 1a and Table 1b. Daily continuous returns of the two panels of Markets are presented as calculated using standard return. We note the non normality of returns is confirmed for all countries by the Jarque-Bera statistic based on Skewness and Kurtosis. The negative values for the Skewness for all markets (except Spain) indicate that data are skewed left showing by this long left tail relative to the right tail. The statistics prove also that all returns series are negatively biased and display excessive kurtosis.

\section{Estimation Results}

the requirement for advance of the GARCH family model, the employ of Nelson (1991) in the form of exponential GARCH (EGARCH) model, which not just examine the exclusive of the impact but in addition its negativity and positivity. We measure the marginal models: the AR-GARCH type models for asset return series.

Table 2. Marginal copula AR(1)/EGARCH(1,1)

\begin{tabular}{|c|c|c|c|c|c|c|}
\hline & $\begin{array}{l}\text { Saudi } \\
\text { Arabia }\end{array}$ & Russia & Kuwait & Qatar & Wti & Brent \\
\hline $\mathrm{C}$ & $0.0007^{* *}$ & $0.000765^{*}$ & 0.0003 & $0.0006^{* *}$ & 0.00173 & $-0.0002^{* *}$ \\
\hline $\mathrm{AR}(1)$ & & $0.0909^{* *}$ & $0.02573^{* *}$ & $0.53^{* *}$ & 0.0062 & $0.0155^{* *}$ \\
\hline $\operatorname{AR}(2)$ & & 0.011 & & & & \\
\hline $\mathrm{AR}(3)$ & $0.0084 * *$ & 0.0054 & & $0.17184 *$ & & \\
\hline $\operatorname{AR}(4)$ & $0.0186^{* *}$ & $0.036986^{*}$ & $0.0141^{* * * *}$ & & 0.00052 & $0.006^{* * *}$ \\
\hline $\operatorname{AR}(5)$ & & & $0.0121 * *$ & $0.2402^{* * * *}$ & & \\
\hline $\operatorname{AR}(6)$ & & 0.0061782 & $0.0141^{* *}$ & & $0.00132^{* * *}$ & \\
\hline $\operatorname{AR}(7)$ & $0.0076^{* *}$ & $0.01332^{* *}$ & $0.01416 * *$ & & & \\
\hline $\mathrm{AR}(8)$ & $0.011^{* *}$ & $0.00212^{* *}$ & $0.0150 * *$ & $0.020^{* *}$ & & $0.00314^{* *}$ \\
\hline $\mathrm{AR}(9)$ & & & $0.0160^{* *}$ & $0.2890 * *$ & & $0.00144^{* *}$ \\
\hline $\mathrm{AR}(10)$ & $0.0069^{* *}$ & & & & & \\
\hline K & $-0.24^{* *}$ & -0.17308 & -0.117 & -0.148 & -0.07225 & -0.0439 \\
\hline GARCH(1) & 0.9704 & 0.97692 & 0.9856 & 0.7613 & 0.98998 & 0.9937 \\
\hline $\mathrm{ARCH}(1)$ & 0.1691 & 0.14844 & -0.1298 & 0.65467 & 0.10713 & 0.1020 \\
\hline Leverage(1) & -0.0775 & -0.055523 & -0.0066 & & -0.04157 & -0.0479 \\
\hline
\end{tabular}

Note: *Statistical significant at the $10 \%$ level. **Statistical significance at the $5 \%$ level. ***Statistical significance at the $1 \%$ level. 


\begin{tabular}{|c|c|c|c|c|c|c|c|}
\hline & US & Japan & China & Germany & France & Italy & Spain \\
\hline $\mathrm{C}$ & $0.008 * *$ & $0.00013^{*}$ & 0.0033 & $0.0003^{* *}$ & 0.0001 & $-0.0004^{* *}$ & $\begin{array}{l}0.0002 * \\
*\end{array}$ \\
\hline $\operatorname{AR}(1)$ & & & & $0.0472^{* *}$ & 0.0062 & $0.075^{* *}$ & $0.131^{* *}$ \\
\hline $\operatorname{AR}(2)$ & $0.0084 * *$ & & & & & & \\
\hline $\operatorname{AR}(3)$ & $0.0186 * *$ & & & & & & \\
\hline $\operatorname{AR}(4)$ & & 0.000529 & 0.034181 & 0.0349 & 0.003 & & \\
\hline
\end{tabular}

$\operatorname{AR}(5)$

\begin{tabular}{|c|c|c|c|c|c|c|c|}
\hline $\operatorname{AR}(6)$ & 0.002812 & & & & 0.00093 & & \\
\hline $\operatorname{AR}(7)$ & 0.020812 & $0.0076^{* *}$ & & 0.0133 & 0.022 & & $0.004^{* *}$ \\
\hline $\mathrm{AR}(8)$ & & $0.011^{* *}$ & $0.045^{* *}$ & $0.020^{* * *}$ & & $0.018^{* * *}$ & $0.010^{* * * *}$ \\
\hline $\mathrm{AR}(9)$ & & & & $0.009 * *$ & & $0.009^{* *}$ & \\
\hline $\operatorname{AR}(10)$ & & -0.0069 & $-0.10230 *$ & & & $0.009^{* *}$ & \\
\hline K & -0.016255 & $-0.24^{* *}$ & 0.98648 & 0.0003 & $-0.122^{* * *}$ & $-0.064 * *$ & $-0.985^{* * *}$ \\
\hline GARCH(1) & 0.10686 & 0.98998 & 0.1419 & 0.9993 & $0.9821^{* * *}$ & $0.991 * *$ & $0.119^{* * * *}$ \\
\hline $\mathrm{ARCH}(1)$ & 0.98048 & 0.10713 & -0.02233 & 0.0851 & $0.1297^{* * *}$ & $0.130 * *$ & $-0.07^{* *}$ \\
\hline Leverage(1) & -0.1351 & -0.0415 & -0.05552 & 0.0275 & 0.0275 & -0.053 & -0.118 \\
\hline
\end{tabular}

Note: *Statistical significant at the $10 \%$ level. **Statistical significance at the $5 \%$ level. $* * *$ Statistical significance at the $1 \%$ level.

Table 2 presents the results of the marginal models. A good description of these models has been given by Fan and Yao (2003) and Abdmoulah (2009). This paper uses daily data of a larger number of Arab stock Kuwait, Tunisia, Dubai, Egypt, Qatar, Jordan, Abu Dhabi, Bahrain, Morocco and Oman using daily data from indices. The approximate calculation GARCH coefficients assure the difference constraints, indicating that the GARCH models are not misspecified. There are signs of a long memory with autoregressive terms of upper order which are statistically significant. The results indicate a strong relationship between volatility and markets performance.

Consequent, we apply the dependence structure between crude oil and the stock market returns. We calculate the different copula functions and we present the smallest Likelihood (LL), the Akaike information criterion (AIC) and the Bayesian information criterion (BIC). The selection of the copula is presented in Table $3 a$; Table $3 b$ (the copula parameter estimates and the tail dependence coefficients). 


\section{1) Macrothink}

International Journal of Accounting and Financial Reporting ISSN 2162-3082

Table 3a. Estimation of the joint copula parameters and tail dependence (the West Texas Intermediate (WTI))

\begin{tabular}{clllllll} 
Parameters & $\begin{array}{l}\text { Clayton } \\
\text { copula }\end{array}$ & $\begin{array}{l}\text { Gaussian } \\
\text { copula }\end{array}$ & $\begin{array}{l}\text { Student } \\
\text { copula }\end{array}$ & $\begin{array}{l}\text { Symmetric } \\
\text { Joe- Clayton } \\
\text { copula }\end{array}$ & $\begin{array}{l}\text { Clayton } \\
\text { copula }\end{array}$ & $\begin{array}{l}\text { Student } \\
\text { copula }\end{array}$ & $\begin{array}{l}\text { Symmetric } \\
\text { Joe- } \\
\text { Clayton } \\
\text { copula }\end{array}$ \\
\cline { 2 - 8 } & US-Wti & Japon-wti & China-wti & Germany-wti & France-wti & Italy-wti & Spain-wti \\
\hline$\rho_{\lambda_{u}}$ & 0.0253 & 0.0088 & 1.3031 & 0.9519 & 0.1562 & 0.2529 & 1.036 \\
\hline \multicolumn{1}{l}{$\lambda_{L}$} & 0 & 0 & 0 & 0 & 0 & 0 & 0 \\
\hline & 0.122 & 0.122 & 0 & 0.121 & 0.121 & 0.122 & 0.122 \\
\hline AIC & -108.9788 & -110.6967 & -75.6344 & -117.404 & -113.2639 & -113.2639 & -100.6288 \\
\hline BIC & -102.3462 & -112.2177 & -65.3322 & -111.6558 & -115.4955 & -115.4955 & -103.0719 \\
\hline LL & -54.4891 & -55.3481 & -37.8170 & -58.7017 & -56.6317 & -50.3141 & -50.3141 \\
\hline
\end{tabular}

\begin{tabular}{|c|c|c|c|c|c|}
\hline Parameters & $\begin{array}{l}\text { Gaussian } \\
\text { copula }\end{array}$ & $\begin{array}{l}\text { Clayton's } \\
\text { copula }\end{array}$ & $\begin{array}{l}\text { Gaussian } \\
\text { copula }\end{array}$ & $\begin{array}{l}\text { Symmetric } \\
\text { Clayton copula }\end{array}$ & Joe- \\
\hline & $\begin{array}{l}\text { Saudi } \\
\text { Arabia-Wti }\end{array}$ & Russia-Wti & Qatar-Wti & Kuwait-Wti & \\
\hline $\begin{array}{l}\rho \\
\lambda_{u}\end{array}$ & 0.0106 & 0.9507 & 2.2340 & 0.7179 & \\
\hline \multirow[t]{2}{*}{$\lambda_{L}$} & 0 & 0 & 0 & 0 & \\
\hline & 0.122 & 0.122 & 0.1221 & 0.121 & \\
\hline$A I C$ & -105.583 & -88.4488 & -102.0869 & -88.0245 & \\
\hline$B I C$ & -130.611 & -84.6661 & -106.0411 & -84.8330 & \\
\hline LL & -65.30537 & -44.2241 & -51.04326 & -44.0120 & \\
\hline
\end{tabular}




\section{Mll Macrothink}

International Journal of Accounting and Financial Reporting ISSN 2162-3082 2019, Vol. 9, No. 1

Table $3 b$. Estimation of the joint copula parameters and tail dependence (Brent crude oil price)

\begin{tabular}{clllllll}
\hline Parameters & $\begin{array}{l}\text { Clayton } \\
\text { copula }\end{array}$ & $\begin{array}{l}\text { Gaussian } \\
\text { copula }\end{array}$ & $\begin{array}{l}\text { Student } \\
\text { copula }\end{array}$ & $\begin{array}{l}\text { Symmetric } \\
\text { Joe- } \\
\text { Clayton } \\
\text { copula }\end{array}$ & $\begin{array}{l}\text { Clayton } \\
\text { copula }\end{array}$ & $\begin{array}{l}\text { Student } \\
\text { copula }\end{array}$ & $\begin{array}{l}\text { Symmetric } \\
\text { Joe- } \\
\text { Clayton } \\
\text { copula }\end{array}$ \\
\cline { 2 - 8 } & $\begin{array}{l}\text { US- } \\
\text { Brent }\end{array}$ & $\begin{array}{l}\text { Japon- } \\
\text { Brent }\end{array}$ & $\begin{array}{l}\text { China- } \\
\text { Brent }\end{array}$ & $\begin{array}{l}\text { Germany- } \\
\text { Brent }\end{array}$ & $\begin{array}{l}\text { France- } \\
\text { Brent }\end{array}$ & $\begin{array}{l}\text { Italy- } \\
\text { Brent }\end{array}$ & $\begin{array}{l}\text { Spain- } \\
\text { Brent }\end{array}$ \\
\hline $\begin{array}{c}\rho \\
\lambda_{u}\end{array}$ & 0.75941 & 0.90107 & 0.0013 & 1.3438 & 0.8449 & 1.6891 & 1.036 \\
\hline$\lambda_{L}$ & 0 & 0 & 0 & 0 & 0 & 0 & 0 \\
\hline \multirow{2}{*}{$A I C$} & -77.5484 & 0 & -103.7940 & -115.7728 & -100.5894 & 112.2746 & -100.5202 \\
\hline BIC & -79.4198 & -90.0103 & -102.8237 & -119.1060 & -114.3361 & 119.4486 & -107.7550 \\
\hline LL & -38.7739 & -41.49678 & -51.8967 & -57.8861 & -50.2945 & -50.3141 & 50.259 \\
\hline
\end{tabular}

\begin{tabular}{cllll}
\hline Parameters & $\begin{array}{l}\text { Gaussian } \\
\text { copula }\end{array}$ & $\begin{array}{l}\text { Clayton's } \\
\text { copula }\end{array}$ & $\begin{array}{l}\text { Gaussian } \\
\text { copula }\end{array}$ & $\begin{array}{l}\text { Symmetric Joe- } \\
\text { Clayton copula }\end{array}$ \\
\cline { 2 - 5 } & $\begin{array}{l}\text { Saudi Arabia } \\
\text { - Brent }\end{array}$ & Russia- Brent & $\begin{array}{l}\text { Qatar } \\
\text { Brent }\end{array}$ & - Kuwait- Brent \\
\hline $\begin{array}{c}\rho \\
\lambda_{u}\end{array}$ & 0.0106 & 1.7508 & 0.0199 & 0.91238 \\
\hline$\lambda_{L}$ & 0 & 0 & 0 & 0 \\
\hline & 0.122 & 0 & 0.1221 & 0 \\
\hline AIC & -105.5837 & -88.4488 & -88.024 & -77.2586 \\
\hline BIC & -130.6111 & -84.6661 & -84.8330 & -100.2019 \\
\hline LL & -54.3321 & -44.2241 & -44.0120 & -50.1007 \\
\hline
\end{tabular}

We note that Qatar, Saudi Arabia and Kuwait indicate correspond dependence structures between oil price and stock market returns, as represented by the Gaussian copula. Germany, 
Kuwait and Spain indicate same dependence structures described by the Symmetric JoeClayton copula. The Student copula gives a better fit for US, Japan and France. Focusing on copula parameters, for all countries we see that the copula parameter is positive indicating that all stock market returns and oil price changes are positively correlated. Lescaroux and Mignon (2008) have studied the relationships between oil and stock prices for emerging countries. They find some evidence of positive causality from oil prices to stock prices in some GCC countries. Jones, al (1996) use quarterly data to verify whether market reaction Changes in oil prices may be justified by the change in expected returns in USA, Japan, and Canada. They find a stable and negative relationship between changes in oil prices and Returns of stock market indices. This relationship is more relevant in the case of Japan than in Canada. Also, these authors show that current prices and staggered oil prices negatively affect stock returns.

We consider the effect of contagion and transmission of volatility between the oil and stock markets. Also, the coefficients are significance at conventional levels. Delayed oil volatility affects strongly market volatility to: France and Kuwait during the entire period; France and during the pre-crisis period and France and Brazil after the crisis. Ratti, (2008) analyze the impacts of oil prices on stock market returns and volatility relationship. Using the same methodology as Sadorsky (1999) and Jouini (2013), that oil prices have a statistically significant on the return on equity in one-month returns of the same stock at different lags.

Aloui et al. (2013) find indication of significant and symmetric dependence for the oil-exchange rate pairs considered. This study proves that positive dependence between oil prices and Gulf Countries stock markets. As expected, the copula parameters are important in by oil exports than oil importers. For example, the Clayton Symmetric Joe- Clayton parameter is larger in Kuwait than in Germany and the Gaussian copula parameter is stronger in Saudi Arabia than in Japan. A possible explanation is the effects of aggregate demand uncertainty on stock markets in oil-exporting countries are much stronger and more persistent than in oil-importing countries. Wang et al. (2013) determined oil price shocks and stock market for oil-importing and oil-exporting countries. This study proves, the magnitude of response by stock market in a country to oil price shocks highly depend on whether the country is a net importer or exporter in the world oil market, and in case changes in oil price depends on the level of interest of oil to national economy, in addition the net position in oil market and oil price changes.

This study helped show nature of tail dependence which is an important potential dimension of contagion. If contagion is a non-linear, as suggested by this study, it may then be inappropriate to think that rejecting the correlation-breakdown hypothesis may be a proof to maintain a stable dependence structure without conducting further research.

\section{Conclusion}

In this paper, we posed to analyse financial contagion by means of a methodology that goes beyond a simple correlation analysis. Correlation is generally known to increase during markets turmoil and remains sensitive to asymptotic and non-linear dependence properties. Our approach enabled us to avoid any form of misspecifying contagion episodes and defining extreme results. It allows for achieving its aims by using copula approaches. After having used 
crude oil prices stock markets index returns, we showed dependence structures during financial turmoil. This approach proves that tail dependence structural breaks are important features of contagion. Nevertheless, it is important to caution that these changes are not imperatively detected by changes in correlations.

\section{References}

Abdmoulah, W. (2010). Testing the evolving efficiency of Arab stock markets. International Review of Financial Analysis, 19(1), 25-34.

Akpan, E. (2009). Oil price shocks and nigeria's macro economy. Journal of Economics, 4(2), 12-19.

Aliyu, S. R. U. (2011). Impact of Oil Price Shock and Exchange Rate Volatility on Economic Growth in Nigeria: An Empirical Investigation. Research Journal of International Studies, 2(4), 23-32.

Aloui, R., Ben Aïssa, M. S., \& Nguyen, D. K. (2013). Conditional dependence structure between oil prices and exchange rates: A copula-GARCH approach. Journal of International Money and Finance, 32(4), 719-738.

Ang, A., \& Bekaert, G. (2002). International Asset Allocation with Regime Shifts. Review of Financial Studies, 15(4), 1137-1187.

Bae, K., Karolyi, G., \& Stulz, R. (2003). A New Approach to Measuring Financial Contagion. Review Financial Studies, 16(3), 717-763.

Bertero, E., \& Mayer, C. (1989). Structure and Performance: Global Interdependence of Stock Markets Around the Crash of October 1987. C. E. P. R. Discussion Papers, p. 307.

Boyer, B., Gibson, M., \& Loretan, M. (1999). Pitfalls in Tests for Changes in Correlation. Working Paper, Board of Governors of the Federal Reserve System.

Caillault, C., \& Guegan, D. (2005). Empirical estimation of tail dependence using copulas: Application to Asian markets. Quantitative Finance, 5(5), 489-501.

Chesney, F., \& Jondeau, E. (2000). Does Correlation Between Stock Returns Really Increase During Turbulent Period?. Working Paper, Banque de France.

Chukwu, I. (2011). How verdict on 86 oil wells affect Rivers, Akwa Ibom economies. Business Day, p.12.

De Melo Mendes, B. V. (2005). Asymmetric extreme interdependence in emerging equity markets. Applied Stochastic Models in Business and Industry, 21(16), 483-498.

Embrechts, P., Hoing, \& Juri, A. (2003). Using copulae to bound the value-at-risk for functions of dependent risks. Finance and Stochastics, 7, 145-167.

Fan, J., \& Yao, Q. (2003). Nonlinear Time Series: Nonparametric and Parametric Methods. Springer, New York. 


\section{$\triangle 1$ Macrothink}

International Journal of Accounting and Financial Reporting

ISSN 2162-3082

2019, Vol. 9, No. 1

Forbes, K., \& Rigobon, R. (2002). No Contagion, Only Interdependence: Measuring Stock Markets Comovements. Journal of Finance, 57, 2223-2261.

Ghosh, S. (2011). Examining crude oil price - Exchange rate nexus for India during the period of extreme oil price volatility. Applied Energy, 88(5), 1886-1889.

Gronwald, M. (2008). Large oil shocks and the us economy: Infrequent incidents with large effects. Energy Journal, 29(1), 151-171.

Hartman, P., Straetmans, S., \& de Vries, C. (2000). Asset market linkages in crisis periods Erasmus. Working Paper.

Hougaard, P. A. (1986). Class of multivariate failure time distributions. Biometrika, 73, 671-678.

Iwayemi, A., \& Fowowe, B. (2011). Impact of Oil Price Shocks on Selected Macroeconomic Variables in Nigeria. Energy Policy, 39(2), 603-612.

Jones, C. M., \& Kaul, G. (1996). Oil and the stock markets. Journal of Finance, 51(2), 463-91.

Jouini, J. (2013). Return and volatility interaction between oil prices and stock markets in Saudi Arabia. Journal of Policy Modeling, 35(6), 1124-1144.

Juri, A., \& Wuthrichts, M. V. (2002). Copula convergence theorems for tail events. Insurance: Mathematics and Economics, 30(3), 405-420.

King, M., \& Wadhwani, S. (1990). Transmission of Volatility Between Stock Markets. Review of Financial Studies, 3, 5-33.

Lardic, S., \& Mignon, V. (2008). Oil prices and economic activity: An asymmetric cointegration approach. Energy Economics, 30(3), 847-855.

Longin, F., \& Solnik, B. (2001). Extreme correlations in international Equity Markets. Journal of Finance, 56, 649-676.

Mahmoud, H. (2009). Oil Price Shocks and Monetary Policy Aggregates in Nigeria: A Structural Var Approach. MPRA Paper No. 25908.

Mork, K. A. (1989). Oil and the Macroeconomy when Prices Go Up and Down: An Extension of Hamilton's Results. Journal of Political Economy, 97, 740-744.

Narayan, P. K., Narayan, S., \& Prasad, A. (2008). Understanding the oil price-exchange rate nexus for the Fiji islands. Energy Economics, 30(5), 2686-2696.

Nelsen, R. (1999). An Introduction to Copulas. Springer, New York.

Ning, C. (2010). Dependence structure between the equity market and the foreign exchange market-A copula approach. Journal of International Money and Finance, 29(5), 743-759.

Olomola, P. A., \& Adejuno, A. V. (2006). Oil price shocks and macroeconomic activities in nigeria. International Research. Journal of Finance and Economics, 3, 28-34. 


\section{Macrothink}

International Journal of Accounting and Financial Reporting

ISSN 2162-3082 2019, Vol. 9, No. 1

Park, J. W., \& Ratti, R. A. (2008). Oil price shocks and stock markets in the U.S. and 13 European countries. Energy Economics, 30(5), 2578-2608.

Patton, A. (2006a). Estimation of multivariate models for time series of possibly different lengths. Journal of Applied Econometrics, 21(2), 147-173.

Patton, A. (2006b). Modelling asymmetric exchange rate dependence. International Economic Review, 47(2), 527-556.

Patton, J. A. (2001). Estimation of multivariate models for time series of possibly different lengths. Economics Discussion, pp. 2001-2017. University of California.

Ramchand, L., \& Susmel, R. (1999). Volatility and Cross Correlation Across Major Stock Markets. Journal of Empirical Finance, 5(4), 1998.

Reboredo, J. C. (2011). How do crude oil prices co-move? A copula approach. Energy Economics, 33(5), 948-955.

Regnier, E. (2007). Oil and energy price volatility. Energy Economics, 29, 405-427.

Rodriguez, J. C. (2007). Measuring financial contagion: A Copula approach. Journal of Empirical Finance, 14, 401-423.

Sadorsky, P. (1999). Oil Price Shocks and Stock Market Activity. Energy Economics, 21(5), 449-469.

Wang, Y., Wu, C., \& Yang, L. (2013). Oil price shocks and stock market activities: Evidence from oil-importing and oil-exporting countries. Journal of Comparative Economics, 41, 1220-39.

\section{Copyright Disclaimer}

Copyright for this article is retained by the author(s), with first publication rights granted to the journal.

This is an open-access article distributed under the terms and conditions of the Creative Commons Attribution license (http://creativecommons.org/licenses/by/4.0/) 